\title{
Solar Drying Techniques And Performance Analysis: A Review
}

\author{
A.C. Jambhulkar, V.B. Pawar, S.B. Pawar, A.S. Dharwadkar, \\ P. S. Pandure, S. P. Gadewar \\ (Department Of Mechanical Engineering, M. E. S. College Of Engineering, S.P. Pune Unuversity-411001, \\ India)
}

\begin{abstract}
The demand for the fossil fuels is increasing day by day, hence the available sources of fossil fuels are reducing. Therefore we require an alternative energy source to fulfill our various demands. Solar energy is one of the alternative to conventional energy sources, also it is available easily. The process of removing moisture from product is known as drying. For drying of agricultural product solar energy can be used. It can be used most efficiently by using solar dryer, as solar dryer reduce the time required for drying and also improves quality and life of the product to be dried. There is need to developed cost effective solar dryer in which different agricultural product can be dried. It should be commercialized. This paper includes review on different types of solar dryer and effect of environmental parameter like solar radiation, ambient temperature etc on performance.
\end{abstract}

Keywords: Drying, fossil fuels, moisture, radiations.

\section{Introduction}

Drying of agriculture products have large significance in food processing industries to increase their life without compromising its nutritional values. Drying is the process of removing moisture from the product. As the prices of conventional fuels are increasing it has lead us to find an alternative. Solar energy is one of the alternative. Drying practices of agriculture products in economically emerging countries are mostly conventional, which varies with the geographical conditions and the type of crops. Solar energy can be utilized for drying. Nowadays solar dryers are widely used for drying of agricultural products. A well designed solar dryer can overcome the disadvantages of traditional sun drying and the quality of dried product can be improved. Various types of solar dryers have been developed and experimented in various regions of the tropics and subtropics. The performance of solar dryer depends on various parameters. By controlling some of the parameters the performance of solar dryers can be improved [1]. Broadly speaking, solar dryers can be distinguished as natural convection and forced convection dryers. In natural convection dryers the flow is established by buoyancy induced flow, while in forced convection solar dryers the flow is provided by using fans that are operated either by electricity or fossil fuels. Natural convection solar drying needs lower investment, although it is not easy to control the drying temperature and the drying rate may be restricted. However, due to limited capacity, most natural convection solar dryers are suitable for household use only [2].

\section{Open Sun Drying System}

This method is the most common method for drying the crops to increase their life. Drying is done by spreading the crops in a thin layer on the mat and crops are exposed to direct sunlight. This method is unsuitable for large amount of crops processed by large firms. Jain and Tiwari [3] developed the mathematical model for open sun drying by studying the behavior of open drying system for different agricultural products. They observed that for cauliflower and potato slice the rate of moisture transfer was high. They found that, the rate of moisture removal, crop temperature is dependent upon ambient conditions. This method has various disadvantages such as large area requirements, more manpower, reduced quality of product.

\section{Direct Solar Dryer}

In this method, direct solar dryers are used to dry the product. The best example of direct solar dryer is box type or cabinet dryer. In direct type, the product is dried by directly exposed to the solar radiations. The only difference between open drying and direct drying is the product is covered with the glass. Solar radiations falls on the dryer and some of them are trapped inside the cabinet because of the glass. This is same as greenhouse effect [4]. This increases the temperature of the product to be dried. The glass cover decreases the direct convective losses to the ambient and this helps in increasing the temperature of agriculture product kept inside the dryer. These are mostly natural convection dryers as the flow of air inside the cabinet is established by buoyancy induced flow, takes place because of temperature difference between inlet and outlet. Construction of 
direct dryers includes a small cabinet which is well insulated and it is covered by glass at the top. Zomorodian et al. [5] proposed the another way of using cabinet type dryer. In cabinet type dryer solar radiations is the main source of energy for removing moisture from products. The dryer include an drying cabinet, the collector and a blower. As the solar radiations are absorbed, the crop temperature inside the cabinet increases and drying initiates. By using glass cover the direct convective losses are reduced. Al-Juamily et al. [6] constructed a cabinet type direct solar dryer as shown in Fig. 1. He performed various tests on it and found that, the temperature is the main factor that dries the product. The relative humidity was also less. However, its solar drying technique affected when sunlight was not available.

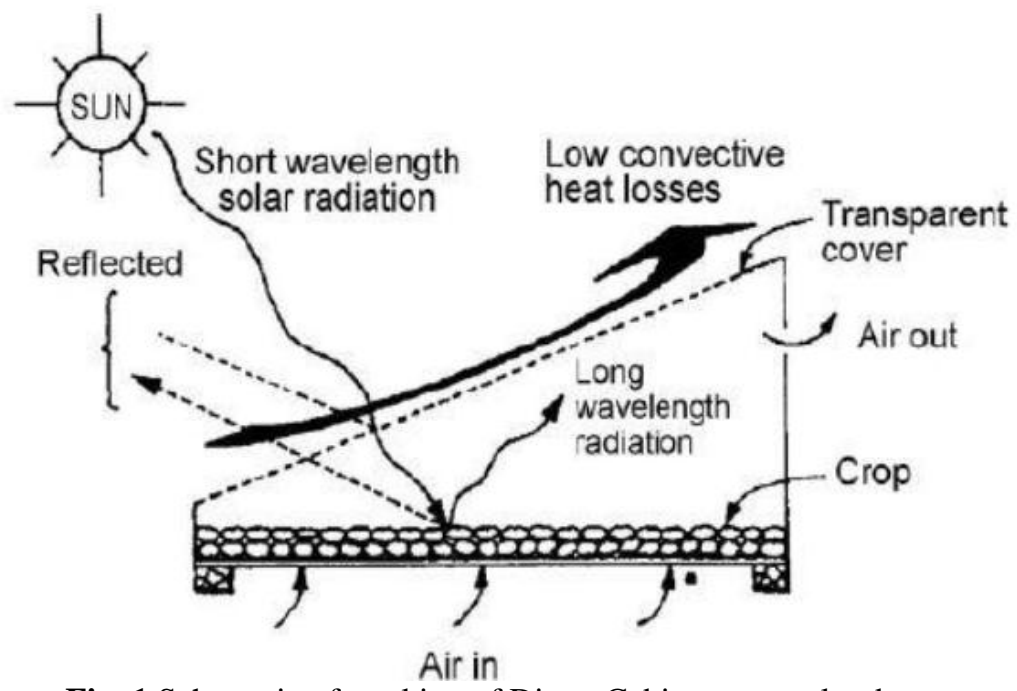

Fig. 1 Schematic of working of Direct Cabinet type solar dryer.

\section{Indirect Solar Dryer}

In an indirect solar dryer as shown in Fig.2, heat from sun is initially gathered by solar collectors where the air inside is get heated. This heated air is then made to flow into the dryer cabinet where drying is to be done. The heated air is passed into the cabinet by using fans or blowers Construction includes an solar collector connecting to a insulated cabinet. The cabinet is a closed vessel which has vent provided for removal of moist air. In indirect types of solar dryer the quality of product is improved [7].

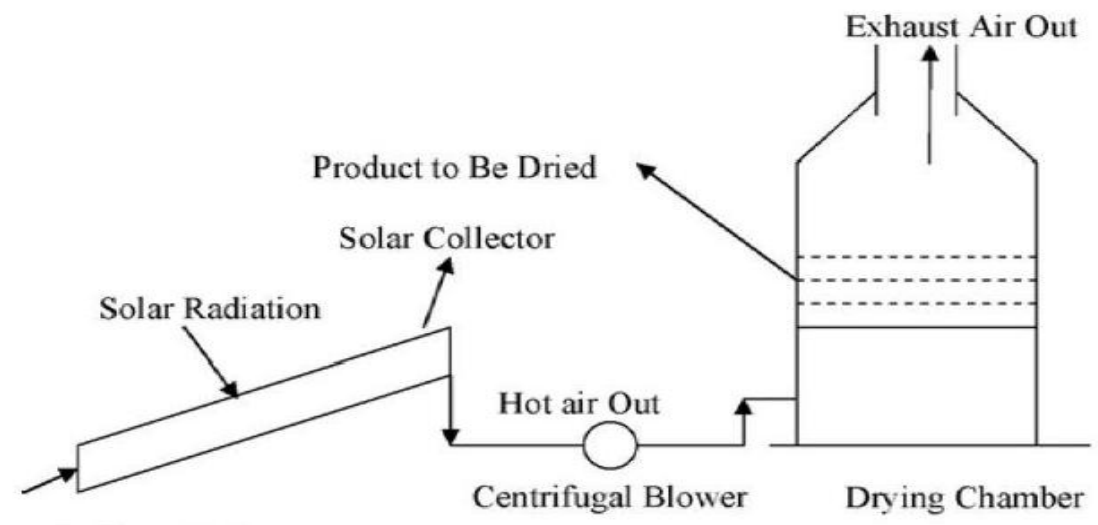

Ambient Air In

Fig. 2 Schematic of working of indirect solar dryer [7].

Panghavane et al. [1] designed and manufactured a solar dyer having a natural convection air flow including solar air heater. The dryer was used to dry e grapes. An absorber is used as air heater consisting of glass cover, insulation, frame and insulation. Air was made to pass through an air duct made of aluminium under the absorber. It was observed that the variables on which mass flow rate of air depends are collector design, prevailing wind conditions, incident solar radiations and ambient air temperature. Also air velocity inside the collector varies along with the temperature difference between inlet and outlet of collector. It was observed that 
the drying air flow rate rises with rise in atmospheric air temperature by virtue of thermal buoyancy inside the collector as shown in Fig. 3.

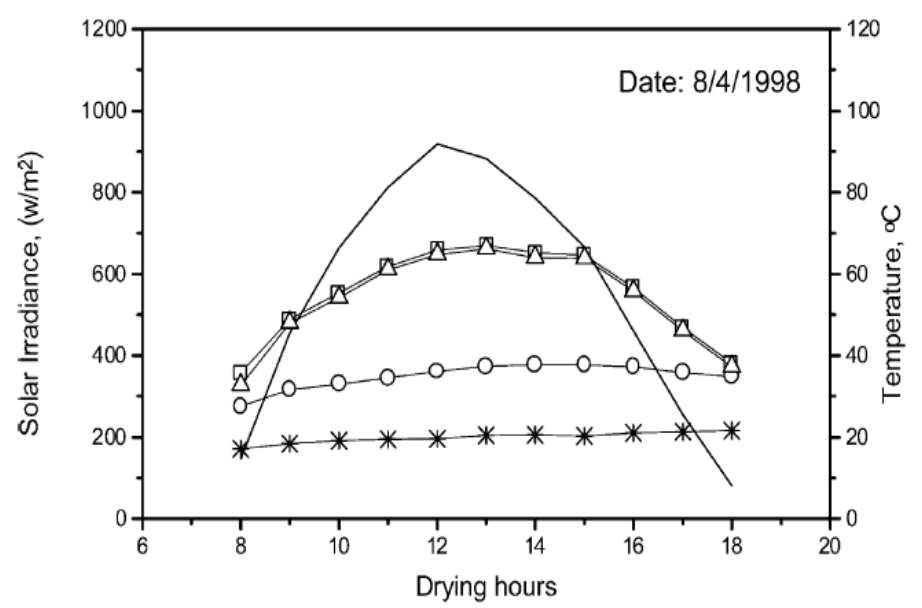

Fig. 3 Diurinal variation of solar irradiance and temperature with time

Koyunchu T. [2] performed thermal analysis for natural convection greenhouse dryer to estimate thermal efficiency and heat gain in load and no load conditions as shown in Fig. 4. Different experimentations were conducted on dryer including opening and closing of chimney to know the effect of chimney on air flow as shown in Fig. 5. Mass flow rate of air increased with the use of chimney due to rise in air flow velocity. It was found that these dryers are most suitable for areas like rainy and high relative humidity climate.

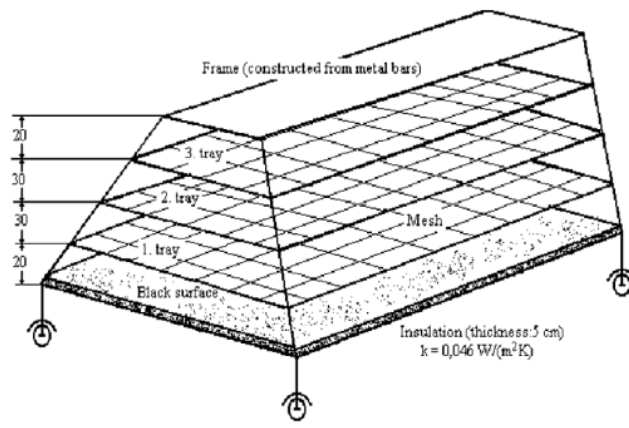

Fig. 4 Schematic of soar dryer

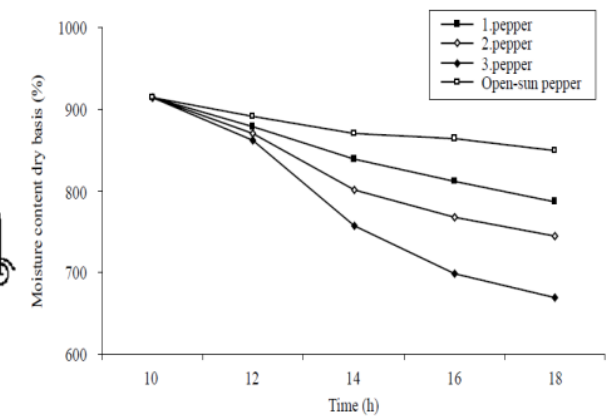

Fig. 5 Moisture content variation with drying time.

Sreekumar et al. [7] did experimentations on cabinet type indirect solar dryer. The dryer was coupled with fans to blow air. An absorber plate was used with an selective paint of absorptivity 0.92 . The temperature obtained during experimentation were not more than $78.1^{\circ} \mathrm{C}$ and $56.6^{\circ}$ respectively at no load with and without fan. From Fig. 6 it is found that the temperature of air within cabinet increased above atmospheric temperature when loaded. The rise in temperature above ambient was between $10.8^{\circ} \mathrm{C}$ to $39.8^{\circ} \mathrm{C}$. Also relative humidity was changed from $51 \%$ to $72 \%$. Velocity of air was maintained at $1.2 \mathrm{~m} / \mathrm{s}$. During initial hours of operation the drying rate was very fast and then it gradually decreased. The cost analysis done had shown that, the use of solar dryer was $42 \%$ more economical than electric dryer for drying of bitter gourd. 


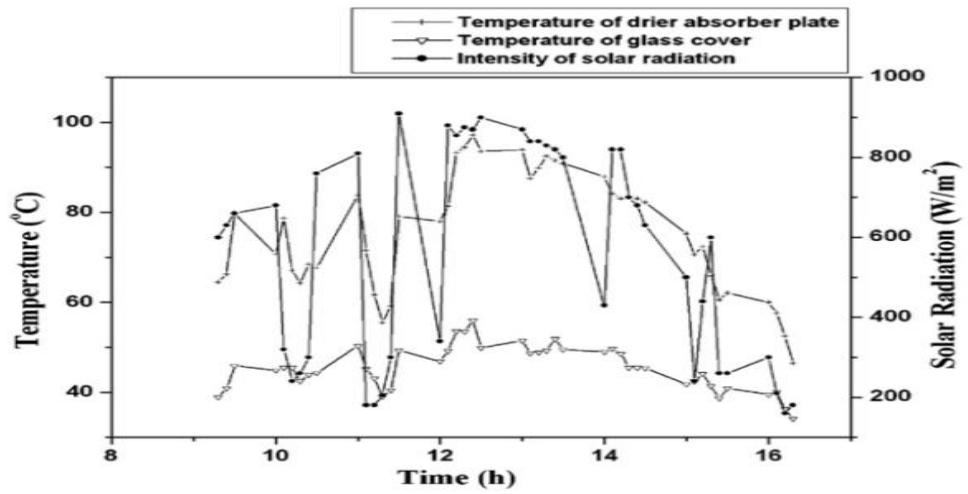

Fig. 6 Variation of absorber plate and glass cover temperature with solar radiation.

\section{Forced Convection Dryers}

L. Bennamoun and A. Belhamari [8] studied a simple, efficient and economical solar batch dryer (forced convection) for crops. It is found that increase in collector surface and heated air decreases the drying time while the influence of the dimension and total weight of the dried product was not much significant as shown in Fig. 7. It was found that by using a blower the results were improved. It allowed use of the dryer in adverse climatic conditions.

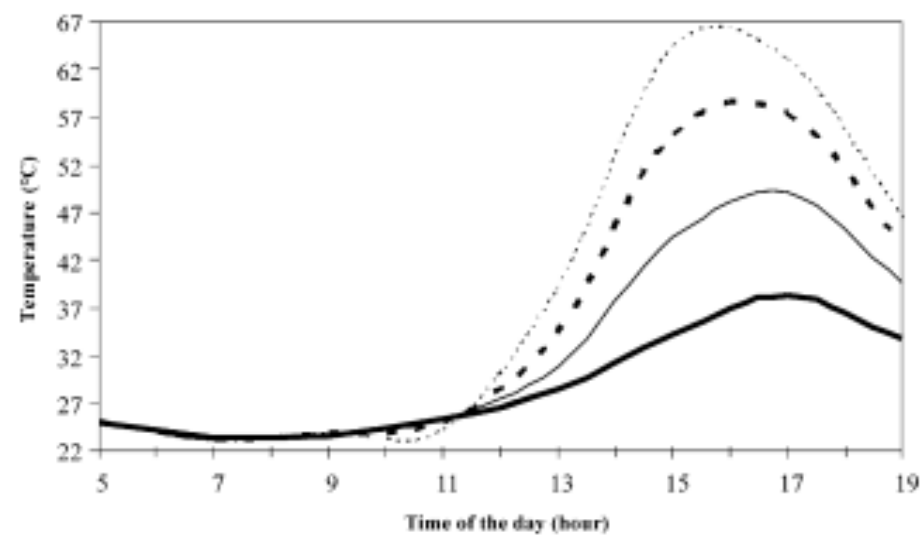

Fig. 7 Influence of collector surface on the product temperature.

Tiwari et al. [9] did thermal modeling for evaluating the coefficient of convective mass transfer for jiggery drying in greenhouse dryer under forced convection condition. Convective mass transfer coefficient was calculated from greenhouse room air temperature, jiggery temperatures, relative humidity and mass evaporated. Coefficient of convective mass transfer was varied from $1.3 \mathrm{~W} / \mathrm{m}^{2} \mathrm{~K}$ to $1.46 \mathrm{~W} / \mathrm{m}^{2} \mathrm{~K}$ which was higher than the narural convection mode as shown in Fig. 8. It was reported that firstly the coefficient of convective mass transfer is more and it reduces as drying process progresses. 


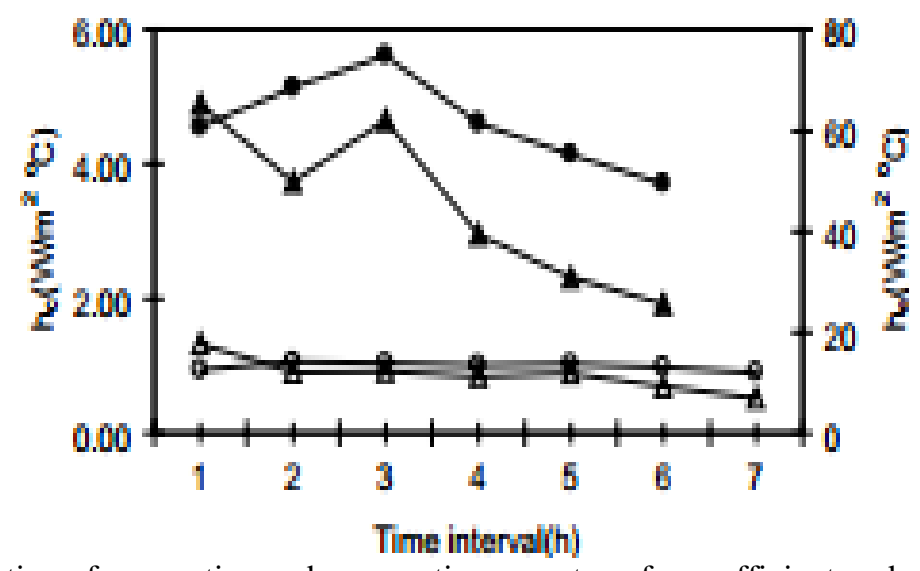

Fig. 8 Hourly variation of convective and evaporative mass transfer coefficient under natural and forced convection for first day of drying

\section{Conclusion}

- Drying, a fundamental procedure in conservation of crops and in some industries can be performed using solar radiations as the primary source of power. The amount of power needed for dryers depends on the product to be dried and the technique used. Solar drying not only plays a significant role in keeping food and agricultural products from deterioration but also improves their quality.

- From the study of various papers it is observed that the temperature obtained in cabinet type natural convection direct solar dryer ranges between $60^{\circ} \mathrm{C}$ to $80^{\circ} \mathrm{C}$ while that of indirect forced convection dryer ranges between $80^{\circ} \mathrm{C}$ to $95^{\circ} \mathrm{C}$.

- The review of literature review suggested that the performance of solar dryer is dependent on incident solar radiation and atmospheric conditions. Also the design of solar dryer plays an important role in achieving require drying characteristics. The inclusion of solar collector provide better performance than when products are directly exposed to sun light in solar dryer.

- The more of the studies performed are focused on experimental analysis of the solar dryer. However, before commercializing the solar dryers, computer simulation models need to be done to understand the short and long terms performance of drying systems. Also benefits of integration of auxiliary heating arrangements need to be assessed to estimate round the clock behavior of solar dryer.

\section{References}

[1]. D. Pangavhane, R. Sawhney, P.Sarsavadia, Design, development and performance testing of a new natural convection solar dryer, Energy, Vol. 27,2002,. pp. 579-590

[2]. A. Sreekumar, P. Manikantan, K. Vijayakumar, Performance of indirect solar cabinet dryer, Energy Conversion Management, 49,2008. pp1388-1395

[3]. A. S. Mujumdar, S.P. ong, S.V. Janganm and C. L. Hii, Solar drying: fundamentals, applications and innovations, ISBN: 978-98107-3336-0.

[4]. Zomorodian, D. Zare, H. Ghasemkhani, Optimization and evaluation of a semi-continuous solar dryer for cereals (Rice, etc), Desalination, vol. 209, ,2007,pp. 129-135.

[5]. T. Koyuncu, An investigation on the performance improvement of greenhouse-type agricultural dryers, Renewable Energy, vol. 31,2006,pp.1055-1071

[6]. P. Chauhan, A. Kumar, Heat transfer analysis of north wall insulated greenhouse dryer under natural convection mode, Energy xxx , 2016, pp. 1-11.

[7]. R. Daghigh and A. Shafieian, An experimental study of a heat pipe evacuated tube solar dryer with heat recovery system, Renewable Energy, vol. 96,2016 , pp. 872-880

[8]. G. N. Tiwari, S. Kumar, O. Prakash, Evaluation of connective mass transfer coefficient during drying of jiggery, Journal of food Engineering, vol. 63, 2004.pp. 219-227

[9]. L. Bennamoun, A. Belhamari, Design and simulation of a solar dryer for agricultural products, Journal of Food Engeneering , vol.59, 2003, pp. 259-266

[10]. D. Jain, G. N. Tiwari, Thermal aspects of open sun drying of various crops, Energy, vol. 28, 2003,pp.37-54.

[11]. P. Gbaha, H. Y. Andoha, J. K. Sarakaa, B. K. Koub, S. Toure, Experimental investigation of a solar dryer with natural convection heat flow, Renewable Energy, Vol.32,2007, pp. 1817-1829

[12]. E.J. Khalil, A. Jabbar, N. Khalifa, T. A. Yassen, Testing of the performance of a fruit and vegetable solar drying system in Iraq, Desalination 209, ,2007. pp. 163-170

[13]. M.A. Basunia, T. Abe, Thin-layer solar drying characteristics of rough rice under natural convection, Journal of Food Engineering, vol. 47,2001,pp. 295-301 